\title{
A self-determination perspective on IT-based citizen advisory support
}

\author{
Giesbrecht, Tobias ; Pfister, Joachim ; Schwabe, Gerhard
}

\begin{abstract}
In public advisory services, the individual's satis-faction depends less on extrinsic factors (e.g., monetary rewards) than on their inner needs fulfillment. Cur-rently used IT-systems supporting citizen advisory serv-ices neglect these intrinsic needs of their users, hence insufficiently fostering their satisfaction. In this paper, we aim to close this gap by assessing the design requirements needed to develop value-added IT-systems for citizen advisory services. We thus refer to self-determination theory to analyze current literature perspectives on how to design adequate IT-systems fostering users' basic needs. We follow a design science approach and implement these requirements in a software prototype, and evaluate them qualitatively in a user study with real-world advisors and citizens. Our preliminary results show that this approach promises to reveal the design requirements that matter in citizen counseling, signifying an important step toward developing a conceptual IT systems design model.
\end{abstract}

DOI: https://doi.org/10.1109/HICSS.2012.83

Posted at the Zurich Open Repository and Archive, University of Zurich

ZORA URL: https://doi.org/10.5167/uzh-55695

Conference or Workshop Item

Accepted Version

Originally published at:

Giesbrecht, Tobias; Pfister, Joachim; Schwabe, Gerhard (2012). A self-determination perspective on IT-based citizen advisory support. In: 45th Hawaii International Conference on System Science, Wailea, Maui, Hawaii, 4 January 2012 - 7 January 2012, 2501-2510.

DOI: https://doi.org/10.1109/HICSS.2012.83 


\section{A Self-Determination Perspective on IT-based Citizen Advisory Support}

\author{
Tobias Giesbrecht \\ University of Zurich \\ giesbrecht@ifi.uzh.ch
}

\author{
Joachim Pfister \\ University of Zurich \\ pfister@ifi.uzh.ch
}

\author{
Gerhard Schwabe \\ University of Zurich \\ schwabe@ifi.uzh.ch
}

\begin{abstract}
In public advisory services, the individual's satisfaction depends less on extrinsic factors (e.g., monetary rewards) than on their inner needs fulfillment. Currently used IT-systems supporting citizen advisory services neglect these intrinsic needs of their users, hence insufficiently fostering their satisfaction. In this paper, we aim to close this gap by assessing the design requirements needed to develop value-added IT-systems for citizen advisory services. We thus refer to selfdetermination theory to analyze current literature perspectives on how to design adequate IT-systems fostering users' basic needs. We follow a design science approach and implement these requirements in a software prototype, and evaluate them qualitatively in a user study with real-world advisors and citizens. Our preliminary results show that this approach promises to reveal the design requirements that matter in citizen counseling, signifying an important step toward developing a conceptual IT systems design model.
\end{abstract}

\section{Introduction and Background}

IT-enabled work practices are commonly used in public administration front and back offices, and continue to flourish due to numerous eGovernment initiatives. Despite all self-service offers put forward by the different governments worldwide, the personal service encounter of citizens with their government represented by public employees is still of immense importance. In this context, appropriate IT-based support has to be established to keep up with the changing needs of the citizens and with the continuing modernization of the public administration. In this paper, we focus on Faceto-Face counseling services, where citizens, entering a novel life circumstance, seek advice from public administration's employees to resolve their governmentrelated issues. These citizens aspire to holistically enhance their actual social situation, e.g., expecting a child or moving into a new town. They seek advice as they often are aware of their lack of information, but can't explicate the underlying problems (also referred to as anomalous state of knowledge [3]), which is a prerequisite for effective problem solving.

When investigating citizens' satisfaction with the
IT-support of services, researchers in information system research concentrate on the individual's system use in organizational contexts. Intention to use and (actual) system use are taken as common measures to obtain indicators for a system's acceptance and therefore its real success (cf. [15]). These measurement concepts are discussed in detail in the research literature (originating from service marketing research) and focus on the pragmatic quality, which primarily targets the system's characteristics to foster the individual work performance, i.e., perceived usefulness and perceived ease of use (for an extensive overview see [8]).

Looking at the dyadic service encounter of citizen advisory services, today's models for measuring user satisfaction are often inadequate. On the one hand, some do not sufficiently consider both participants, but focus mainly on one, e.g., SERVQUAL [19]. On the other hand, corresponding models do not incorporate users' inner motivation, e.g., UTAUT [31]. Even though this is not always made explicit, many approaches in information system research investigating intention to use are goal-oriented, focusing on the extrinsic motivation of human behavior, e.g., rewarddriven action. A number of studies, comparing work motivation in the public and the private sector, pointed out, that public employees are less motivated by monetary (or other extrinsic) rewards than private ones ([1] [4], [12], [20]). Furthermore, public employees, on different organizational levels, do not seem to be convinced of the incentive and the rewarding effect of extrinsic motivators, such as performance-related pay ([18]). When taking the organizational context of public administrations into account, Rainey stated, that the additional problem arise of "how to motivate employees in systems which constrain administration of those incentives" ([20]). In this paper, we address this topic and suggest, that one has to take on another perspective on work motivation and therefore user behavior to understand the rationales behind user satisfaction of IT-systems supporting public administrators giving advice to citizen. That is why we suggest to consider the users' underlying needs motivating their activities the advisor's as well as the client's. This approach fits well into the motivational perspective, which Malone [17] states as one of four important perspectives, on 
should take on when designing information systems' interfaces.

Current literature on the developments of ITsystems supporting advisory encounters in general, and advisor-citizen interactions in particular, proposes a number of design requirements proven to be successful. To assess these current design requirements with respect to user needs, we provide in this paper a review of scientific findings on how IT-based citizen advisory services can support the needs fulfillment of both citizens and advisors. We use the self-determination theory (SDT) [9] as a lens to explain the basic needs of the involved individuals. Deci and Ryan, the authors of this theory, postulate that humans are driven by the motivation to lead a self-determined life, and claim three innate psychological needs, the fulfillment to which they constantly aspire: competence, autonomy, and relatedness. Every human action is intrinsically motivated by the expectation that the result or the action itself will fulfill certain basic human needs in a particular context. Accordingly, these needs being fulfilled - at least to a certain extent - will result in increased satisfaction [10].

The question arises then: Which design requirements for an IT-system supporting co-located citizen advisory services assist the fulfillment of users' basic needs. By its answering, we want to broaden the understanding of advisory information system design, and provide future developers with a useful catalogue of design requirements for IT systems, the implementation of which should lead to substantially more satisfied users. Secondly, by doing so, we heed the call for "kernel theories" for design [33]. As we will show, selfdetermination theory is well suited to serve as such a kernel theory for designing advisory support systems.

In the following section, we present our research approach to achieve the defined objectives and describe how the data was collected.

\section{Research Design and Data Collection}

The question for essential design requirements emerged in the course of a larger research program investigating IT-support within co-located citizen advisory services. Therein, a first prototype had been developed to confirm the general feasibility of supporting citizen advisory services by means of an IT-system; the evaluation was done in a real-world setting assisting the counseling of pregnant women (cf. [5], [23], [26]).

Based on the findings of this prior work, we first reviewed the current state of design requirements proposed in the extant literature on IT-based citizen advisory support systems. To assess these requirements regarding the self-determination theory, we map them in section 3, onto the basic psychological human needs for competence, autonomy, and relatedness. We engage in a "design and evaluate" cycle [14] to assess (and enhance) the current design requirements to see if they support in practice the fulfillment of the users' basic needs. Thereto, we specify a (real-world) context of use (section 4), develop appropriate design solutions according to the design requirements (section 5) and evaluate them in a user test (section 6).

Context of use: We report from our comprehensive exploratory research (cf. [30]) to specify the context of use, i.e., student counseling services. Thereby, we followed the Needs Driven Approach [27] to assess the advisors' work environment and based our interviews on Wilson's model for information behavior [37] to assess students' and advisors' information seeking behavior. For that purpose, a total of 13 interviews (with two advisors and 11 students) were conducted. Following our self-determination focus, we assessed the current situation regarding the basic users' needs for competence, autonomy, and relatedness to disclose deficiencies, and also assess practices that should be preserved.

Design solutions: According to the literature-based design requirements, we developed, cf. in section 5, appropriate design solutions and implemented them in a software-prototype intended to support advisors and students in their advisory-related activities.

Evaluation: To assess the developed design solutions, we conducted 11 counseling sessions with two advisors from the international relations office (IRO) of the authors' university and 11 students (where they used the developed IT tool). These sessions took place in a small meeting room, lasted typically $20-30 \mathrm{mi}-$ nutes, and were observed by two researchers focusing on the activities and interactions of the individual participant. The advisors had received a training lesson beforehand (about 45 minutes), where they became acquainted with the manipulation of the IT tool's functionalities and were informed of the corresponding advisory objectives. Subsequent to the counseling session, both students and advisors completed similar questionnaires, after which they were interviewed additionally. Both the questionnaires and the interviews contained elements of their perceived acceptance of the IT-system (UTAUT, [31]), their perceived satisfaction (yield shift theory, [6]) and their perception of the system's pragmatic and hedonic qualities (AttrakDiff, [13]). Following an explorative approach, using qualitative data, we focus on the interviews and the observations of the participants' actual behavior, which together signify our primary data sources. In section 6 , we report on these evaluation results to discuss the literature-based requirements from the self-determined users' perspective, and develop a final catalogue of design requirements, whose implementation should 
plausibly foster the users' need fulfillment, i.e., their satisfaction.

\section{Self-Determination Theory (SDT) in Cit- izen Advisory Support}

The SDT proposed by Deci and Ryan [9]) is rooted in motivational psychology, and provides an empirically founded theoretical framework to describe the basic psychological needs and their influence on human behavior. It claims three innate psychological needs (competence, autonomy, and relatedness) that all humans pursue at any given time to maintain their psychological health and well-being. Accordingly, we will consider all these aspects from the perspective of the citizens as well as that of the advisors.

Competence refers to the aspect of successfully dealing with one's environment. In general, this concerns having sufficient information and skills to resolve any occurring issue on one's own. In the context of a counseling service, the client and advisor both want to be competent during their encounter, e.g., influencing the course of their collaboration. Whereas for the citizen this could comprise arriving at a certain state of knowledge, the advisor predominantly would have the more complex need for sufficient professional, methodical, and social skills to provide sound advice (cf. [10]).

Autonomy refers to freedom of choice and being able to lead a self-determined life. This basic need corresponds well with the counselor's goal of enabling citizens to resolve any government-related problem occurring within their individual life situation (cf. [35]). The concept of autonomy further refers to the constant urge to be the cause of one's own actions, in contrast to the feeling that extrinsic forces cause them. For this reason, the provision of choice and acknowledging people's inner experience enhances their feeling of self-initiation, of being the initiators [9].

Relatedness refers to the possibility of interacting with others. During the counseling, this need for interaction has to be satisfied. Reis et al. [21] identify the major types of social activity that might plausibly contribute to a general sense of relatedness. Regarding advisory encounters, the following are considered to be relevant: (1) communicating about personally relevant matters, (2) participating in shared activities, (3) having a group of friends with whom one can spend informal social time, (4) feeling understood and appreciated, (5) avoiding conflicts that create distance and feelings of disengagement with significant others, and (6) avoiding self-conscious or insecure feelings that direct attention toward the self and away from others. If IT systems are applied in advisory situations, they should support these activities in some way in order that the users' sense for relatedness is fostered.

By applying the self-determination theory, we intend to take a wider perspective and seek to complement our understanding of advisors and citizens as they behave during a counseling session. Thus, in the subsequent paragraphs, we explain how information systems supporting citizen advisory services can foster the advisors' and the citizens' corresponding needs. We therefore analyze the correspondent requirements proposed by the current research literature on (citizen) counseling and assess the extent to which they support the fulfillment of the users' need for competence, autonomy, and relatedness. When referring to the elaborated design requirements, later in this paper, we denote them with "DR1" to "DR11."

\subsection{Advisor's and Citizen's Need for Compe- tence}

Competence refers to successfully dealing with one's environment. According to SDT, any involved individual within the dyadic advisor-client encounter strives for competence. Citizens' frequent reason for seeking advice from public authorities is the gap in their knowledge of governmental support regarding their present life circumstance. Apart from their basic need of improving their current situation, citizens are often not able to articulate what they really want (anomalous state of knowledge, cf. [3]). In these situations, human advice is superior to computer-based advice, e.g., electronic services on governmental web appearances, since a human can empathize with another person and elicit hidden needs in a question-answer dialog. Schmidt-Rauch et al. [24] and Schwabe et al. [26] refer to this as supporting the elicitation of the citizen's implicit needs (DR1).

The collaborative nature of the counseling session is one of the most important characteristics due to the fact that: (1) a common understanding of the client's problems has to be established and (2) information and knowledge of solutions has to be transferred from the expert (=advisor) to the layperson (=client). Schwabe et al. [26] purport that collaborative processes evolve and therefore cannot be structured beforehand in detail; the authors thus propose that the state of collaboration must be transparent at all times (DR2). They claim that in order to interact actively within the advisory encounter, both the advisor and the citizen must be able to understand the state of their collaboration at any time, e.g., which results have been achieved, how still open issues can be addressed etc. We also refer to this as process transparency.

By integrating the client into the problem-solving process, their perception of being responsible for the 
decisions agreed upon, as well as the final advisory result, will be enforced. According to Deci and Ryan [9], this feeling of responsibility is essential for the heightening of their perceived competence. We refer to this as supporting joint problem-solving (DR3). Schmidt-Rauch et al. [24] connect this design requirement with the recognized trend within service-oriented marketing [16] that clients become co-creators of value (cf. [32], [36]). Within the first step of the joint problem-solving process, where a common understanding of the citizen's (true) needs is established, the advisor and the citizen individually create their own mental models, which have to be harmonized [26]. Accordingly, the ability to externalize and share the users' mental models is a prerequisite for establishing competence, denoted as (DR4).

The need to feel competent to advise citizens on their governmental concerns (from the advisors' perspective) and being able to decide on the right "products" (from the citizens' perspective) directly calls for information quality as a pre-condition. This, for instance, is confirmed by DeLone and McLean [10], who nominate information quality as an aspect of IS success within their IS Success Model. In addition, the advisors' usage of IT is strongly influenced by their fear of acting incompetent, i.e., not being able to answer the client's questions due to inadequate access to information. Thus, an important design requirement is to $\mathrm{im}$ prove information quality (DR5) (cf. [24]). For the organizational context of citizen advisory, Schenk and Schwabe [23] describe correspondent design requirements on a more detailed level. They complement the advisory service by integrating offline and online information sources (DR5.1), integrating local, regional, state and federal information sources (DR5.2) and, integrating internal and external information (DR5.3).

\subsection{Advisor's and Citizen's Need for Autonomy}

In the context of co-located citizen advisory services, a central influencing factor of the individual's autonomy appears in the conflict between providing possibilities of choice and structuring of the advisory process. From a "counseling as collaboration" perspective [25], there should be features for the users to create and develop their process structures during their ongoing collaboration [26], even though some predetermined structure is necessary to support mutual understanding of the current (process) status and the upcoming activities. We refer to this as support evolution of process structure during collaboration (DR6).

According to their individual roles within the ongoing collaborative problem-solving process, both advisors and citizens must have, to a variable extent, the capability to alter the direction of the counseling. The advisor should guide citizens through the process, and thereby act as a mentor, eliciting their true needs and conjointly developing suitable solutions to fulfill these needs. Although the advisor needs sufficient possibilities of control to navigate through the process, the clients - in order to feel as equal collaboration partners - must still be given the possibility of intervening in the advisory process, which, in turn, will augment their feeling of self-determination.

An important aspect of assisting citizens to successfully resolve problems on their own is to personalize the information provided in the counseling session. Increased personalized information leads to a higher autonomy for citizens as a result of having increased options [2]; we refer to this as supporting the personalization of information (DR7).

\subsection{Advisor's and Citizen's Need for Related- ness}

Relatedness refers to interacting, feeling connected, and experiencing caring for others. Deci and Ryan [9] claim that intrinsic motivation will be more likely to flourish in contexts characterized by a sense of secure relatedness. Within citizen counseling, both participants must be supported in fulfilling their need for relatedness. In the following paragraphs, we use the social activities that contribute to an individual's sense of relatedness (see above, denoted (1) to (6), cf. [21]), in order to assess the design requirements in this regard.

The previously stated requirement of supporting the personalization of information (DR7) is a first prerequisite for communicating personally relevant matters (1). Schwabe et al. [26] posit that the IT-support should allow the user to establish a personal relationship during, and develop it after, the interaction (DR9). This requires establishing an intimate ambiance, where the advisor listens and responds to the citizen. This can be supported by the exchange of personal information, as it fosters trust [11], and by integrating "more trusted" information sources as external (DR5.3) or community-based (DR8) information.

The social activity of participating in shared activities (2) is understandably met by the design requirement of supporting joint problem-solving (DR3). With the diffusion of Web 2.0, a practical resource for resolving and/or discussing problems without the explicit contact with an advisor appears in the form of (online) communities, e.g., forums, wikis, or blogs. Regarding citizen advisory services, community based information, e.g., discussion forums or rating sites for related services, can offer an additional perspective (during the counseling session) that a public administration is not willing, or not able to, provide itself. Further, communities where citizens can meet with other persons facing 
the same life situation can be used to follow up on issues left open during the session [26]. Accordingly, the integration of Web 2.0 and community-based information (DR8) addresses the social activity of having a group of friends with whom one can spend informal social time (3). For advisors, their colleagues at work signify this group; thus, corresponding IT-means should support the establishing of a "working community" [34].

Supporting the elicitation of the citizen's true needs (DR1) is beneficial for a citizen's feeling of being understood and appreciated (4). Schwabe et al. [26] propose that a verbal discussion on problems and possible solutions is a more natural means of collaboration. The advisor can use his background knowledge and empathize with the citizen to uncover hidden information needs and offer advice not explicitly requested. We refer to this as base the interaction on verbal communication (DR10).

The last two social activities cover the aspects thwarting the sense of relatedness, as avoiding conflict that create distance (5) or avoiding insecure feelings that direct attention toward the self (6). To diminish the advisors' fear of "losing control," i.e., to be perceived as being incompetent in the eyes of the citizen, Bretscher [5] claims that user interfaces should be easy to learn and easy to use (DR11).

Table 1. The literature-based design requirements assigned to the SDT-needs

\begin{tabular}{|l|l|}
\hline & \multicolumn{1}{|c|}{ Resulting Design Requirements } \\
\hline Users' & Need for Competence \\
\hline DR1 & Supporting the elicitation of the citizen's implicit needs \\
\hline DR2 & $\begin{array}{l}\text { Supporting transparency in the states of collaboration (at all times) } \\
\text { / Increase process transparency }\end{array}$ \\
\hline DR3 & Supporting joint problem-solving \\
\hline DR4 & Supporting the externalization and sharing of mental models \\
\hline DR5 & Improve information quality \\
\hline DR5.1 & $\begin{array}{l}\text { Inform the advisory process with offline and online information } \\
\text { resources }\end{array}$ \\
\hline DR5.2 & Integrate local, regional, state and federal information \\
\hline DR5.3 & Integrating internal and external information \\
\hline Users' Need for Autonomy \\
\hline DR6 & Support the evolution of process structure during collaboration \\
\hline DR7 & Supporting the personalization of information \\
\hline Users' & Need for Relatedness \\
\hline DR8 & Include Web 2.0 and community-based information \\
\hline DR9 & $\begin{array}{l}\text { Allow the users to establish a personal relationship among them- } \\
\text { selves during, and develop it after, the interaction }\end{array}$ \\
\hline DR10 & Foster verbal communication in the interaction \\
\hline DR11 & User interfaces should be easy to learn and easy to use \\
\hline
\end{tabular}

Table 1 provides an overview of the derived design requirements for IT-systems supporting co-located citizen advisory services. Thereby, the individual requirement is allocated to the user's respective need for competence, autonomy or relatedness.

\section{Context of Use: Conventional Student Counseling Service}

A major task of the international relations office (IRO) is to give assistance to foreign students, e.g., visa-related issues, finding accommodation, or registering with authorities. Conventional practice is oriented towards providing all relevant information before students arrive. For that purpose, printed information (brochures, leaflets, forms, etc.) is sent to students, and is also presented on the university's web sites. Students can also contact the IRO via e-mail via telephone and during open consultation hours on a first-come, first-served basis.

Face-to-Face advisory services are provided at a counter consisting of a large bar table attached to the wall on which a computer is placed. The student and the advisor stand next to each other so that documents can be placed on the table and the computer screen can be jointly viewed. The advisor sometimes presents the desired information directly on the web sites of an authority. Bookmarks, maintained collaboratively by the advisors, are used very often to navigate quickly to the right site - reflecting the students' recurring information needs.

There is no pre-defined advisory-process. Instead, in most encounters the IRO-advisor respond to questions of the student and answers them in the ensuing dialogue. The results of an advice-giving session are also not documented systematically. Sometimes students take notes (e.g., the URL of the web sites), or they are presented with a printout of the web page or brochures, etc.

In the following sections, we provide illustrative examples of how the dimensions: competence, autonomy, and relatedness of the self-determination theory are addressed by the conventional practice of advicegiving, as seen from the students' and advisor's perspective. The findings are drawn from the observations and interviews, conducted by advisors and students.

\subsection{Competence in Conventional Advice- Giving}

Whereas for students competence signifies having sufficient information to resolve their problems on their own, the advisors' association of the term predominantly refers to the ability to provide sound information.

Within the current work practices, the students constantly suffer from having "insufficient competence." This can be seen in the mainly pure information provision of the IRO-advisors. As the advisors restrict themselves to answering explicit questions and providing 
the corresponding information, students do not get any methodical knowledge to resolve future similar requests on their own. Accordingly, as reported in the interviews, students developed their own strategies comprised of a network of experience-based information sources, e.g., friends, family, online forums and blogs for expatriates. In summary, it seems that the advisors' current practices did not adequately foster the student's perceived competence.

The IRO-advisors' vocational training follows a learn-by-doing principle, i.e., start giving advice and asking colleagues if problems with students' request occur. They also used a bookmark list on the shared computers to profit by the other advisors' experience. Accordingly, the advisors relied (at least in the first few advisory sessions) on the bookmark list and the quality of the information provided there - including nonfunctioning web links. Such an environment where the students could see when advisors had to ask someone for help, or needed to search for solutions due to insufficient information sources, hampered obviously the advisors' need to appear competent in the eyes of their clients.

\subsection{Autonomy in Conventional Advice-Giving}

The individual's sense of autonomy is closely related to the perception of freedom of choice. In conventional student counseling services, the predominant interaction pattern - a question-answer scheme - suggests a distinctive role allocation; the advisor uses his competencies and knowledge to deliver answers and solutions to the student's information need, as interpreted from the question asked.

The students can "control" the advisor's behavior with their questions, i.e., the students can get the desired information personalized to their problems. On the other side of the coin, the observed advisors' behavior shows that they concentrate only on giving answers, but provide no background information that would be vital for related needs. Indirectly, the advisors rationalize their counseling objective of bringing "students to autonomy." In summary, the advisor's autonomy is obviously low in the conventional advisory practice; however, it is unclear if this matches their perception.

\subsection{Relatedness in Conventional Advice-Giving}

Concerning the need for relatedness, the advisor and the student both strive to feel related (1) to one another and (2) to their respective social environment. The conventional work practice of IRO-advisors concentrates, on the students' sense for relatedness; in other words, they a personal relationship with the student for the duration of the counseling session. Accordingly, as evidenced from the questionnaire results, the students highly valued the advisor's social skills with an average of $92 \%$. Notably, students showed in their information seeking behavior that they predominantly referred to information sources from personal experience (e.g., former exchange students or forums for expatriates), the advisors did not refer to this aspect of relatedness.

The advisors' need for relatedness is fulfilled only to a small extent. The examples of the shared bookmark list (see above) signify the main activities fostering relatedness within the actual session. The advisors also criticized the current possibilities of professional interaction and gave rationale regarding unsuitable resources (including IT means) available to them.

\section{Design Solutions: IT-based Advisory Support in Practice}

To assess the literature-based design requirements (cf. Table 1), we contextualized them within the realworld setting of a student counseling service (described in the previous section). We developed appropriate design solutions and implemented them in a softwareprototype. This tool supports the elicitation and documentation of the consulter's needs as well as the proposed solutions. The participants can jointly interact with the tool in order to retrieve and visualize the organization's information configured for this counseling session. In the following paragraphs, the instantiation of the design solutions are described with the help of a real-world scenario, illustrating a student counseling session where the IT tool is used. For the technical implementation, we used Silverlight (XAML) for the UI-Design and C\# with the .NET Framework 3.5 in the backend (details on design following below).

At the beginning of the counseling session, an advisor from the IRO (Sally) and a student (Kate) take their place in front of a large touch-sensitive screen (HP Touchsmart, cf. Figure 1), after which they start talking about Kate's requests. Hearing of Kate's problem how to get a job, Sally opens a new memo card and labels it "getting a job" (DR4, cf. Figure 2). [The memo card contains different functions: 1) The client's request can be noted, 2) Adequate solutions can be added (cf. Figure 3 on the right) and, 3) The card is part of a "drag and drop" construct to support the forming of a personalized advisory process. Therefore, the memo cards act as central element in the application.]

Before Sally starts to solve the first problem, she asks if there are other issues that Kate wants to discuss (DR10). In the course of the conversation, Sally adds two more memo cards, "health insurance" and "public transportation possibilities" (cf. Figure 2). She then 
opens a list in the upper left corner of the screen, noting that there are recurring problems facing students. She mentions to Kate that if she sees some interesting topics, she should click on them to generate pre-completed cards, which they could discuss later (DR1). Finally, Sally groups the memo cards on the screen by shifting them around with her finger, thus establishing a (simple) process structure that suits her and Kate for the subsequent problem-solving (DR 3, 6, 11).

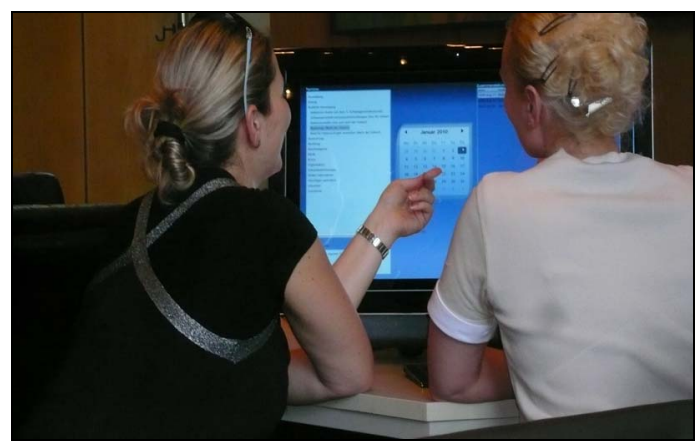

Figure 1: Physical setup

Picking the first memo card "getting a job," Sally shows Kate a website with job offers suitable for students, e.g., part-time with flexible working hours (DR5). For this purpose, she moves the concrete problem memo card with her finger on the "website" icon at the bottom and navigates it to the corresponding screen (cf. Figure 3). By physically keeping hold of the problem and taking it with her into the next advisory phase of designing an appropriate solution, Kate could follow the counseling process more easily. Sally now chooses from a list of governmental, university and, third party websites, as well as online forums for expatriates (DR5, 8) one covering job markets and displays it. After a short discussion of the job category suitable for Kate's situation, Sally adds the web link to the problem memo card (cf. Figure 3, on the right) (DR7).

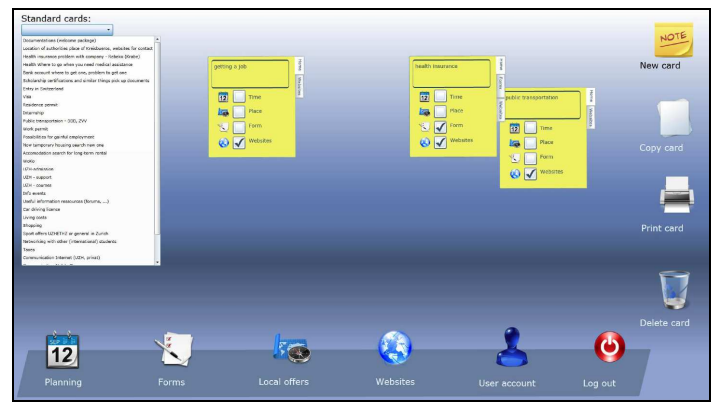

Figure 2: Main screen of the application

They continue to process Kate's problem by reviewing government information on work law. Sally also supplements this information with some additional useful hints from her (DR9), supplementing the solution. Subsequent, they return to the main screen and agree on "closing the card", i.e., end the problemsolving process (DR2).

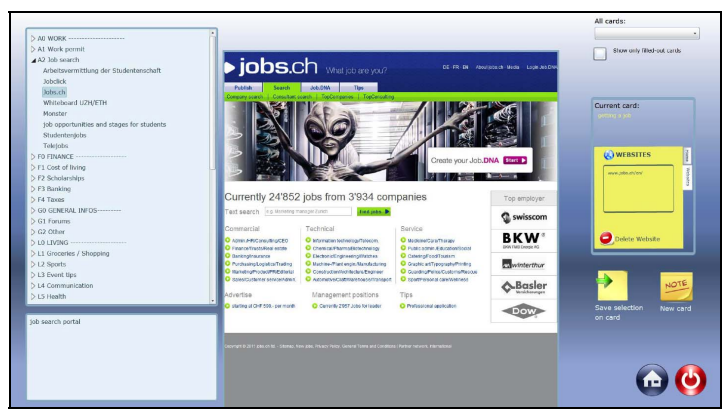

Figure 3: Website screen of the application

In this way, Sally and Kate work through all preliminarily created memo cards. After finishing the last one, Sally explains to Kate that she could either send her all the information that they gathered by email, or she could print it for her. As Kate would like to receive it electronically, she gives Sally her email address. They conclude the advisory session with Sally wishing Kate all the best on her job search.

\section{Evaluation of IT Supported Student Counseling: Self-Determined Users}

The software-prototype comprising the elaborated design solutions (cf. section 5) was evaluated in a test setting, where advisors used the tool to give advice to foreign students regarding their "living and studying in a new country."

Whereas the students in our tests valued their perceived satisfaction with the IT tool well (with an average of $86 \%$ ), the advisors were moderately satisfied (average of 68\%). Although these subjective user statements support the impression that their expectations were met, the users' underlying basic needs were fulfilled to a varying extent. Therefore, we discuss, in the following subsections, the evaluation results in this regard.

\subsection{The Users' Need for Competence}

The students' perception of their competence is that they believe they have the knowledge needed to resolve their problems on their own. In the test sessions, the students valued the information and instructions received as being comprehensible and useful; they also perceived themselves to be competent solving problems using the received information. The students appreciated the links between the problems and the solu- 
tions noted on the memo cards - a significant aspect students felt was absent in the traditional counseling situation. Further, the virtual memo cards made it easier for them to recall the stage of the advisory process (or the distinct problem-solving process "on one card") in which they were currently engaged. In particular, the advisor arrangement of the cards seemed to be a useful structuring aid, not just enhancing the transparency of the advisory process, but also giving students the required knowledge to participate actively.

The advisors' sense of competence focused mainly on (1) competent information provision and (2) professional guidance through the advisory process. As to the first objective, the advisors made extensive use of the (different kinds of) information sources provided, and thus responded more in depth to the students' individual problems. This was described not only by the students as being "more personalized services," but the advisors also described this way of working as a "more satisfying information provision."

Concerning the second part of the advisors' need for competence, their methodical skills, they appreciated the memo cards because of the possibility of structuring the counseling session while still being able to customize it at any time. Although the "memo card"metaphor performed well in this respect, it did not address the advisors' weakness in adopting a proper advisory process (cf. [28]).

A structured problem-solving process can enhance the process's outcome significantly (cf. [29]). As research insights from the last decades in computer supported collaborative work have proven, the process structure cannot be forced onto users by IT means; it is up to advisors to apply the right methodical competencies to lead users through the appropriate advisory process. We therefore propose extending counseling supportive IT with adequate learning functionalities, (1) supporting the advisors' vocational qualification and (2) providing them with methodical support during citizen encounters. We refer to this as supporting learning activities (DR12).

\subsection{The Users' Need for Autonomy}

The observations in our test have shown that the advisor is de facto the only user directly operating the IT tool. However, the students perceived themselves to have sufficient possibilities of influencing the advisory course of action by observing every activity in the information system and having the possibility to intervene whenever necessary. Thus, their perception of autonomy did not appear to suffer. The correspondent measurements of the system's hedonic qualities backed these statements (average of 61\%). Further, the students reported that by using the IT tool, the advisor was able to respond in a more individual way; consequently, they perceived themselves as being more in the advisor's center of attention, be the cause for the advisor's actions.

The advisor, as key user of the IT tool, react in a very sensitive manner regarding the force it exerted, or the freedom of choice it provided in relation to advisory-related activities, e.g., instructions on the advisory process itself. As they experienced in the test sessions, advisors were able to perform every activity they intended to do, and thus did not perceive any restrictions or enforcements by the IT tool.

Even though not noticed by students, the advisors showed clear deficiencies in certain phases of the advisory process, e.g., in verifying whether the advisory goals had been achieved. During the tests, the advisor did not finish the counseling session, for instance, by providing a big picture of the student's problems and corresponding solutions. Instead, they proposed that students should "come back if there were any ambiguities". As IT can provide substantial added value in this respect, we recommend that advisory supportive IT should support the advisory structure with mandatory activities (DR13). This means that important advisory activities, e.g., externalizing the client's needs, would have to be carried out. But to preserve the users (perceived) autonomy, in contrast to a given process structure, advisors and citizens would be free to decide when to accomplish the mandatory activity.

\subsection{The Users' Need for Relatedness}

The students' expectations with respect to their need for relatedness focus mainly on their relationship to the advisor. In the context of citizen advisory services, clients commonly assign the advisors good social skills. In this regard, the students in our test sessions perceived the IT tool as "ideal externalization and documentation of the verbal discussion and the solution finding process." For this reason, the IT tool seemed to fit well in the dyadic advisory encounter, supplementing the personal relationship between the advisor and the student. This is an important objective for advisory supportive IT, considering the fact that deployed IT often acts as a communicational barrier in advisory sessions [22].

Advisors associated with their perception of relatedness in (1) their interaction with the client and (2) their interaction with their colleagues at work. Regarding the former, the observations of the advisors' behavior revealed that they tended to separate the used IT tool from students. This means, that advisors engaged in a intense verbal discussion with students and neglect their task of encouraging students' IT use, thereby integrating them as equal collaboration partners. The 
advisors gave rationale to this behavior by referring to their work motivation as: "get to know people from other cultures and their experiences." Accordingly, the users' conceptions of counseling seem to influence users' behaviors, and IT tools' developers should take this into account.

The second aspect of the advisors' sense for relatedness concerns their professional and social interactions with their colleagues at work. As this refers strongly to the advisors' vocational qualification phase, it could not be assessed in the conducted test. However, the observations of the current work practices (cf. section 4) highlighted the advisors' need for an adequate IT-supported solution. Respective IT support should establish a "learn[ing] community," where the advisors could communicate with one another and interchange professional knowledge (DR14). This has already been suggested by Wang [34] as a requirement for electronic learning system.

Table 2. Final set of design requirements for advisory supportive IT assisting the self-determined users

\begin{tabular}{|l|l|}
\hline \multicolumn{2}{|l|}{ Users' } \\
\hline DR1 & Supporting the elicitation of the citizen's implicit needs \\
\hline DR2 & $\begin{array}{l}\text { Supporting transparency in the states of collaboration (at all } \\
\text { times) / Increase process transparency }\end{array}$ \\
\hline DR3 & Supporting joint problem-solving \\
\hline DR4 & Supporting the externalization and sharing of mental models \\
\hline DR5 & Improve information quality \\
\hline DR5.1 & $\begin{array}{l}\text { Inform the advisory process with offline and online information } \\
\text { resources }\end{array}$ \\
\hline DR5.2 & Integrate local, regional, state and federal information \\
\hline DR5.3 & Integrating internal and external information \\
\hline DR12 & Supporting learn activities \\
\hline Users' & Need for Autonomy \\
\hline DR6 & Support the evolution of process structure during collaboration \\
\hline DR13 & Support structuring with mandatory activities \\
\hline DR7 & Supporting the personalization of information \\
\hline Users' & Need for Relatedness \\
\hline DR8 & Include Web 2.0 and community-based information \\
\hline DR9 & $\begin{array}{l}\text { Allow the users to establish a personal relationship among } \\
\text { themselves during, and develop it after the interaction }\end{array}$ \\
\hline DR10 & Foster verbal communication in the interaction \\
\hline DR11 & User interfaces should be easy to learn and easy to use \\
\hline DR14 & Enable professional interaction among advisors \\
\hline
\end{tabular}

\section{Conclusion}

In this paper, we investigated the design of IT systems supporting co-located citizen advisory services. We took the perspective of self-determined users, i.e., advisors and citizens with their basic psychological needs. By using it, we could complement our preliminary literature-based catalogue of design requirements by additional ones, which would hardly be disclosed otherwise. Thereto, we followed a design science approach; by building a prototype and incorporating appropriate design solutions, we conducted test counseling sessions in a real-world context. Finally, we elaborated a catalogue of design requirements (cf. Table 2), whose implementation should substantially foster user satisfaction.

Basing our approach on the self-determination theory allowed us to broaden our understanding of user satisfaction of IT-systems supporting advisory encounters. We were thus able to build a 'better-founded' design requirements catalogue for respective information systems. With this catalogue and the self-determination theory as kernel, we could take an important step forward in the building of a conceptual design model for citizen advisory support systems (cf. [33]). We suggest that further research should include the assessment and enhancement of the developed catalogue by considering additional models, and describing user satisfaction from other perspectives (e.g., [6], [7], [10]). We believe that the "design and evaluate"-concept, which has proven useful, should be retained.

\section{References}

[1] Anderfuhren-Biget, S., F. Varone, D. Giauque, and A. Ritz, "Motivating Employees of the Public Sector: Does Public Service Motivation Matter?," International public management journal, 13, 3, p. 213-246, 2010.

[2] Aschoff, F.-R., and G. Schwabe, "Online Travel Communities: A Self-Determination Theory Approach”, 2011.

[3] Belkin NJ, R. Oddy, and H. Brooks, "Ask for information retrieval. Part 1: Background and theory", Journal of Documentation, p. 61-71, 1982.

[4] Buelens, M. and H. Van den Broeck, "An Analysis of Differences in Work Motivation between Public and Private Sector Organizations." Public Administration Review, 67, 1, 2007.

[5] Bretscher C., "Design und Implementation eines Bu $\square$ rgerberatungstools im Rahmen des EGovernment”, Diploma thesis, University of Zurich, Institut of Informatics, 2009 .

[6] Briggs, R., B. Reinig, and G. Vreede, "The Yield Shift Theory of Satisfaction and Its Application to the IS/IT Domain", Journal of the Association for Information Systems, 9, $5,2008$.

[7] Carter, L., and F. Bélanger, "The utilization of egovernment services: citizen trust, innovation and acceptance factors", Information Systems Journal, 15, 1, 2005.

[8] Carvalho, C., C. Brito, and J. S. Cabral, "Towards a conceptual model for assessing the quality of public services", International Review on Public and Nonprofit Marketing, 7, 1, Springer, 2010.

[9] Deci, E., and R. Ryan, „The "What" and "Why" of goal pursuits: human needs and the self-determination of behavior", Psychological Inquiry, 11, 4, p. 227-268, 2000. 
[10] Erpenbeck, J., and L. von Rosenstiel, "Handbuch Kompetenzmessung”, Schäfer/Pöschel, Stuttgart, 2007.

[11] Friedman, B., P. Khan, and D. Howe, "Trust on-line". Comm. of ACM, 43, 12, p. 34-40, 2000.

[12] Grant, A., "Employees without a Cause: The Motivational Effects of Prosocial Impact in Public Service," International Public Management Journal 11, 1, p. 48-66, 2008.

[13] Hassenzahl, M., M. Burmester, and F. Koller, “AttrakDiff: Ein Fragebogen zur Messung wahrgenommener hedonischer und pragmatischer Qualität", Mensch \& Computer, Stuttgart, 2003.

[14] Hevner, A., “A Three Cycle View of Design Science Research", Scandinavian Journal of Information Systems, 19, 2, p. 87-92, 2007.

[15] Legris, P., J. Ingham, and P. Collerette, "Why do people use information technology? A critical review of the technology acceptance model", Information \& Management, 40, p. 191-204, 2003.

[16] Lusch, R. and S. Vargo, "The service-dominant logic of marketing: dialog, debate, and directions", M.E. Sharpe, 2006.

[17] Malone, T.W. "Designing organizational interfaces," Proceeding of CHI Systems, p. 66-71, 1985.

[18] Marsden, D. S. French and K. Kubo, "Does performance pay de-motivate, and does it matter?" Center for economic performance, LSE, London, 2001.

[19] Parasuraman, A., V. Zeithaml, and L. Berry, "SERVQUAL: A Multiple-Item Scale for Measuring Consumer Perceptions of Service Quality", Jounral of Retailing, 64, 1, 1988.

[20] Rainey, H., "Reward Preferences among Public and Private Managers: In Search of the Service Ethic", The American Review of Public Administration 16, 1982.

[21] Reis, H., K. Sheldon, S., L. Gable, J. Roscoe, and R. Ryan, „Daily well-being: The role of autonomy, competence, and relatedness", Personality and Social Psychology Bulletin, 26, p. 419-435, 2000.

[22] Rodden, T., Y. Rogers, J. Halloran, and I. Taylor, „Designing novel interactional workspaces tosupport face to face consultations“, Proceeding of CHI 2003, ACM Press, 2003.

[23] Schenk, B., and G. Schwabe, "Understanding the Advisory Needs of Citizens", Proceeding of MKWI, 2010.
[24] Schmidt-Rauch, S., R. Schaer, and G. Schwabe, „From Telesales to Tele-Advisory Services in Travel Agencies", Proceeding of ICIS, 2010.

[25] Schmidt-Rauch, S., and P. Nussbaumer, "Putting value Co-creation into practice: A Case for advisory support ", Proceeding of ECIS, 2011.

[26] Schwabe, G., C. Bretscher, and B. Schenk, "Designing for light-weight collaboration: The case of interactive citizens' advisory services", Proceeding of DESRIST 2010, St. Gallen, 2010.

[27] Schwabe, G., H. Krcmar, "Der Needs Driven Approach - Eine Methode zur Gestaltung von Telekooperation", Proceeding of DCSCW 96, Springer, Heidelberg, p. 69-88, 1996.

[28] Schwabe, G., B. Schenk, and C. Bretscher, "Bedarfsermittlung und Informationsaggregation bei der Bürgerberatung 2.0", Proceeding of Verwaltungsinformatik 2010, Koblenz, 2010.

[29] Simon, H., "The new science of management decision", Prentice Hall, New Jersey, 1977.

[30] Stebbins, R. A., "Exploratory Research in the Social Sciences", Sage Publications, 2001.

[31] Venkatesh, V., M. Michael, G. Davis, and F. Davis, "User Acceptance of Information Technology: Toward a Unified View”, MIS Quarterly, 27, 3, 2003.

[32] von Lucke, J., "Bürgerkoproduktion”, In: Bürgerservices, edition sigma, 2011.

[33] Walls, J., G. Widmeyer, and O. El Sawy, "Building an Information System Theory for Vigilant EIS", information systems research, 3, 1, 1992.

[34] Wang, Y., "Assessment of learner satisfaction with asynchronous electronic learning systems", Information \& Management, 41, p. 75-86, 2003.

[35] Warschburger, P., "Beratungspsychologie", Springer, Berlin, 2009.

[36] Whitaker, G., "Coproduction: Citizen Participation in Service Delivery", Public Administration Review, 40, 3, p. 240-246, 1980.

[37] Wilson, T., "Information Behaviour: An interdisciplinary perspective", Information Processing and Management, 33, 4, p. 551-572, 1997. 